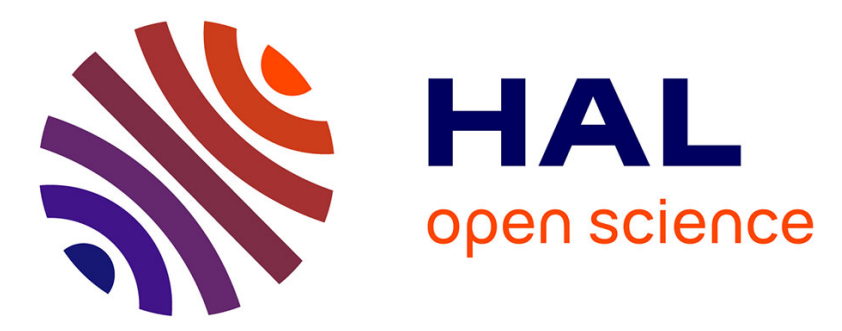

\title{
Pilot scale study of chlorination-induced transport property changes of a seawater reverse osmosis membrane
}

\author{
Axel Ettori, Emmanuelle Gaudichet-Maurin, Pierre Aimar, Christel \\ Causserand
}

\section{To cite this version:}

Axel Ettori, Emmanuelle Gaudichet-Maurin, Pierre Aimar, Christel Causserand. Pilot scale study of chlorination-induced transport property changes of a seawater reverse osmosis membrane. Desalination, 2013, vol. 311, pp. 24-30. 10.1016/j.desal.2012.11.004 . hal-00875977

\section{HAL Id: hal-00875977 \\ https://hal.science/hal-00875977}

Submitted on 23 Oct 2013

HAL is a multi-disciplinary open access archive for the deposit and dissemination of scientific research documents, whether they are published or not. The documents may come from teaching and research institutions in France or abroad, or from public or private research centers.
L'archive ouverte pluridisciplinaire HAL, est destinée au dépôt et à la diffusion de documents scientifiques de niveau recherche, publiés ou non, émanant des établissements d'enseignement et de recherche français ou étrangers, des laboratoires publics ou privés. 


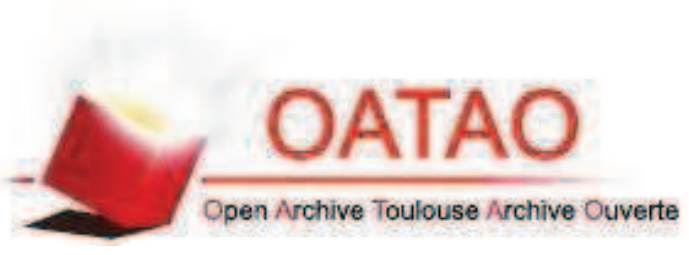

\section{Open Archive TOULOUSE Archive Ouverte (OATAO)}

OATAO is an open access repository that collects the work of Toulouse researchers and makes it freely available over the web where possible.

This is an author-deposited version published in : http://oatao.univ-toulouse.fr/ Eprints ID : 9743

To link to this article : DOI:10.1016/j.desal.2012.11.004

URL : http://dx.doi.org/10.1016/j.desal.2012.11.004

To cite this version :

Ettori, Axel and Gaudichet-Maurin, Emmanuelle and Aimar, Pierre and Causserand, Christel Pilot scale study of chlorination-induced transport property changes of a seawater reverse osmosis membrane. (2013) Desalination, vol. 311 . pp. 24-30. ISSN 0011-9164

Any correspondance concerning this service should be sent to the repository administrator: staff-oatao@listes-diff.inp-toulouse.fr 


\title{
Pilot scale study of chlorination-induced transport property changes of a seawater reverse osmosis membrane
}

\author{
Axel Ettori ${ }^{\mathrm{a}, \mathrm{b}, \mathrm{c}}$, Emmanuelle Gaudichet-Maurin ${ }^{\mathrm{c}}$, Pierre Aimar ${ }^{\mathrm{a}, \mathrm{b}}$, Christel Causserand ${ }^{\mathrm{a}, \mathrm{b}, *}$ \\ a Université de Toulouse, INPT, UPS, Laboratoire de Génie Chimique, 118 route de Narbonne, F-31062 Toulouse cedex 09, France \\ b CNRS, Laboratoire de Génie Chimique, F-31062 Toulouse, France \\ c Veolia Environnement Research and Innovation, Maisons-Laffitte Research Center, Chemin de la digue, BP 76, 78603 Maisons-Laffitte cedex, France
}

\section{H I G H L I G H T S}

A 4" spiral wound reverse osmosis module is exposed to hypochlorite on a long term basis.

Changes in water and salts permeances are similar to those found in lab scale studies.

Hypochlorous acid was confirmed to be the most important factor in membrane modification over time.

Keywords:

Polyamide

RO module

Seawater desalination

Chlorine

Elemental analysis

\begin{abstract}
A B S T R A C T
A pilot-scale study was performed to assess variations of reverse osmosis (RO) membrane water permeance (A) and salt retention $\left(R_{\mathrm{obs}}\right)$ induced by chlorination and to compare them with those observed at the lab-scale. A chlorination protocol was adapted to expose only the surface active layer (an aromatic polyamide) of a composite RO membrane to consecutive free chlorine doses ranging from 40 to $4000 \mathrm{ppm} \mathrm{h}$, at pH 6.9. Along the long-term filtration of seawater, performed with a 4" spiral wound RO module, we monitored the variations of $A$, the decrease of $R_{\mathrm{obs}}$ and the rate of increase of $A$ with time, and found them quantitatively similar to those reported in previous studies performed at the lab-scale under accelerated exposure conditions. The elemental analysis of the feed and permeate streams revealed that the rejection of divalent ions remained constant (ca. 100\%), irrespective of the free chlorine dose reached, whereas the rejection of monovalent ions of the seawater (mainly sodium, chloride and bromide ions) decreased as the exposure dose increased. Overall, transposing the characterization procedure to the pilot-scale further supports that chlorination of PA, under pH conditions usually found in desalination plants (6.9 to 8.0), is controlled by the concentration of $\mathrm{HOCl}$, as observed from elemental analysis of the surface by XPS.
\end{abstract}

\section{Introduction}

Aromatic polyamide-based (PA) composite reverse osmosis (RO) membranes currently account for over $95 \%$ of existing RO desalination plants [1]. As opposed to asymmetric cellulose acetate-based RO membranes, the composite PA RO membranes can be operated under strong acidic and basic conditions, as they exhibit chemical stability across a $\mathrm{pH}$ range of 2-11 at temperatures ranging from 20 to $35{ }^{\circ} \mathrm{C}[2,3]$, and do not suffer from compaction with time making them ideal candidates for long-term use in water treatment applications [4]. The ubiquitous reactivity of the PA film, which provides the water/salt selectivity to the composite RO membrane, in the presence of free chlorine, is widely reported in the literature [5-8]. It can

\footnotetext{
* Corresponding author at: Université de Toulouse, INPT, UPS, Laboratoire de Génie Chimique, 118 route de Narbonne, F-31062 Toulouse cedex 09, France. Tel.: + 33561 5586 90; fax: + 33561556139 .

E-mail address: caussera@chimie.ups-tlse.fr (C. Causserand).
}

hamper to some extent the membrane operating lifetime, e.g. the stability of the permeation flux and salt retention. During on-site operation, the latter is usually due in part to the inability of current cleaning procedures to effectively reduce for example membrane biofouling [9], conversely could be due to a potential irreversible loss of membrane selectivity in the case of an exposure to free chlorine, as demonstrated during long term filtration studies $[10,11]$ Thus, the use of free chlorine as a cleaning agent in RO membrane treatment applications is still questioned.

Insights into the physicochemical properties changes of the PA layer, despite inherent difficulties related to the characterization of a thin film incorporated into a composite material, have mainly been provided by spectroscopy studies [12-14]. In particular, it is commonly assumed that chlorination, following a 2-step electrophilic substitution mechanism favored at acidic $\mathrm{pH}[15,16]$, results in changes in PA chain cohesion energy, also confirmed by recent mechanical and thermal characterization studies $[17,18]$. Ongoing work is focusing on relating the evolutions in the properties of the chlorinated PA layer to water 
and salt transport variations of RO membranes in filtration operating conditions relevant to seawater desalination. RO membrane permeance to water and salt retention were shown, on numerous occasions, to be free chlorine dose and free chlorine solution pH dependent [19]. Recently, it has been reported that the chlorinated PA may undergo a relaxation process, through swelling, which is irreversible as evidenced by an increase of the pure water permeability, with the permeation of an electrolyte [20]. Most of these studies were conducted at the lab-scale, generally by using single solute electrolytic solutions or model seawaters at best.

The aim of the present study was therefore to investigate the relevance of such academic studies on an industrial scale pilot unit. To this end, the water permeance and salt retention were assessed during the long term filtration of a pretreated seawater performed by using 4" RO spiral wound modules. Furthermore, the chlorination of the RO modules was performed under exposure conditions similar to those used previously at the lab-scale, with respect to the active specie, dose range spanned and contact mode. The main objective was to compare the changes of water permeance and salt retention determined at the pilot-scale with a consecutive increase of the free chlorine dose, from 40 to $4000 \mathrm{ppm} \mathrm{h}$, with those reported on membrane samples (surface area of $140 \mathrm{~cm}^{2}$ ) under accelerated exposure conditions $[19,20]$. In addition, this comparison was used to assess the relevance of accelerated exposure conditions, performed at the lab-scale, in predicting potential chlorine-induced performance changes during on-site operation. The influence of each free chlorine dose on the variations of the transport properties was determined at the steady state, owing to long term filtration runs, and a critical exposure dose at which RO selectivity irreversibly decreases below a threshold value of $99.6 \%$, in particular to bromide ions, was determined. In addition, elemental analysis of the ion composition of the permeate enabled to further investigate the role of the permeation of electrolytes on characteristic water permeance variations of chlorinated PA-based RO membranes.

\section{Materials and methods}

\subsection{Membrane}

A commercially available seawater reverse osmosis membrane (SW30HRLE, Dow Filmtec@) was used during this study. As detailed previously [19], this composite membrane possesses a fully aromatic polyamide thin film, the active layer (PA). Elemental analysis (see Section 2.5.1) was performed on membrane samples with sizes of ca. $4 \times 4 \mathrm{~cm}$ which were extracted from an 8 " spiral wound module and stored and rinsed in ultrapure water (UP water from a Millipore MilliQ system, $18.2 \mathrm{M} \Omega \mathrm{cm}$ ). Filtration experiments during the pilot-scale study were performed using 4" spiral wound modules possessing a surface area of $7.9 \mathrm{~m}^{2}$.

\subsection{Desalination pilot plant and seawater composition}

The desalination pilot plant was located near the bay area of the city of Toulon, in the southeast Mediterranean coast of France. It comprised a pretreatment stage and 2 RO modules running in parallel and achieved on average a flow rate of $1 \mathrm{~m}^{3} \mathrm{~h}^{-1}$ (Fig. 1). Furthermore, it was equipped with an automated data acquisition system and on-line measurement instruments, which enabled to monitor continuously seawater flow rate and physicochemical properties, namely conductivity, temperature and $\mathrm{pH}$, at intake, and during the pretreatment and RO stages.

In brief, the pretreatment consisted in a coagulation step which was performed by injecting $1 \mathrm{mg} \mathrm{L}{ }^{-1}$ ferric chloride $\left(\mathrm{FeCl}_{3}\right)$ without any adjustment of the $\mathrm{pH}$ upstream of dual-media filters. Pretreated seawater was collected and stored in a break tank used to feed downstream the 2 RO units running in parallel. Each RO unit (used for the experiment and a control) was composed of one pressure vessel placed vertically which could contain one $4 "$ spiral wound module. RO feed stream (pretreated seawater) was pumped using high pressure pumps to the top of the pressure vessel and flowed from top to bottom. The applied pressure and flow rate were controlled through adjustment of a back-pressure regulating valve. Occasionally, a low level indication in the feed and break tank would cause an automatic shutdown of the pretreatment and/or RO units (see stars in Fig. 4).

Moreover, samples of RO unit feed and filtered seawater were periodically taken for the analysis of the ionic content (see Section 2.5.2). The average concentration of target mono- and divalent ions of the pretreated seawater determined during this study are given in Table 1. Partial ionic balance indicates that the sodium and chloride ions account for ca. $80 \%$ in $\mathrm{M}$ of the ionic content of the pretreated seawater. In addition, the influent contained bromide ions at an average concentration of $69 \mathrm{mg} \mathrm{L}^{-1}$. Bromide ions were specifically monitored with regard to human health issues, as they can form bromate anions, a suspected human carcinogen [21], and due to their reactivity in the presence of chlorine generating halogenation compounds, potentially competing with chlorination species $[22,23]$.

\subsection{Filtration protocol}

Two filtrations runs were performed independently by using two separate pristine 4" RO spiral wound modules from December 2010 to February 2011. The applied pressure and the membrane permeation flux and feed and permeate conductivities were continuously monitored by on-line measurements throughout the chlorination

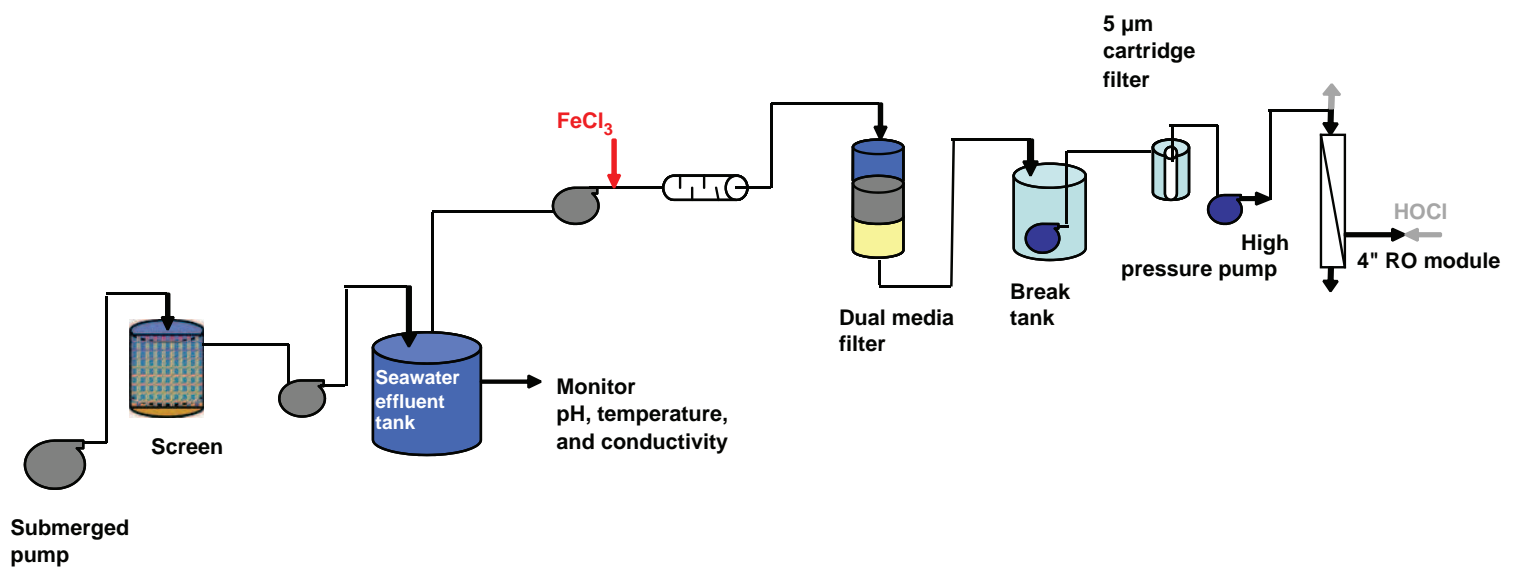

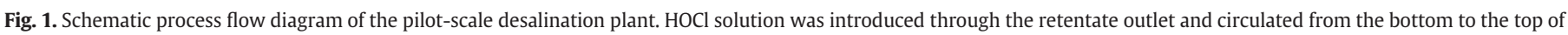
the module, placed vertically, with a peristaltic pump. 
Table 1

Average concentration of target mono- and divalent ions of the pretreated seawater as of December 2010 to February 2011 (Toulon, France).

\begin{tabular}{lc}
\hline Ion & Concentration $(\mathrm{mM})$ \\
\hline Chloride $\left(\mathrm{Cl}^{-}\right)$ & $552 \pm 62.1$ \\
Bromide $\left(\mathrm{Br}^{-}\right)$ & $0.9 \pm 0.1$ \\
Sulfate $\left(\mathrm{SO}_{4}^{2-}\right)$ & $32 \pm 0.79$ \\
Potassium $\left(\mathrm{K}^{+}\right)$ & $10 \pm 1.7$ \\
Sodium $\left(\mathrm{Na}^{+}\right)$ & $473 \pm 58.2$ \\
Calcium $\left(\mathrm{Ca}^{2+}\right)$ & $10 \pm 1.3$ \\
Magnesium $\left(\mathrm{Mg}^{2+}\right)$ & $53 \pm 10$ \\
\hline
\end{tabular}

Determined for a seawater influent with an average conductivity of $56 \mathrm{mS}$ $\mathrm{cm}^{-1}$, temperature of $14.5^{\circ} \mathrm{C}$ and $\mathrm{pH}$ of 8.3 .

procedure which was performed by sequential increments of the free chlorine dose (see Section 2.4). Filtration runs lasted from 3 to 4 weeks, duration which was found to be sufficient to obtain steady state permeation conditions following each successive injection of free chlorine solutions. The RO units were operated at a constant permeation flux $\left(J_{\mathrm{w}}\right)$ of $21 \mathrm{~L} \mathrm{~h}^{-1} \mathrm{~m}^{-2}$, at $20{ }^{\circ} \mathrm{C}$, and with a $13 \%$ recovery corresponding to average conditions found on-site for one module (considering an average recovery of 50\% per pressure vessel which contain up to 6 modules). This recovery factor is optimized to limit the concentration polarization at the surface of the selective membrane and potential fouling. The RO module permeance to water $\left(\mathrm{L} \mathrm{h}^{-1} \mathrm{~m}^{-2} \mathrm{bar}^{-1}, 20^{\circ} \mathrm{C}\right)$ and bulk observed salt retention (\%), transport properties commonly used on-site, were determined by Eqs. (1) and (2), respectively.

$A={ }^{J_{\mathrm{w}}} /_{\left(P_{\mathrm{app}}-\Delta \Pi\right)}$

$R_{\mathrm{obs}}=1-{ }^{\sigma \mathrm{p}} / \sigma_{\mathrm{o}}$

In Eq. (1), $J_{\mathrm{w}}$ is the permeation flux expressed in $\mathrm{L} \mathrm{h}^{-1} \mathrm{~m}^{-2}, \mathrm{P}_{\mathrm{app}}$ is the mean applied pressure across the RO module and $\Delta \Pi$ is the bulk trans-membrane osmotic pressure, both expressed in bar. The osmotic pressure was determined by using the Van't Hoff equation, which can be considered to be accurate for the mono- and divalent salts at the concentration of the seawater (see Table 1). In Eq. (2), $R_{\mathrm{obs}}$ is the observed salt retention (\%) and was determined from the electrolytic conductivity values in the permeate $\left(\sigma_{\mathrm{p}}\right)$ and in the bulk feed $\left(\sigma_{\mathrm{o}}\right)$ measured at $20 \pm 2{ }^{\circ} \mathrm{C}\left(\mu \mathrm{Sm}^{-1}\right)$. Strictly speaking, $R_{\text {obs }}$ is defined by the concentrations expressed in $\mathrm{M}$ or from the total dissolved solids concentration when it can be determined with accuracy, which was not the case here given that the exact composition of the seawater was not determined. No further corrections were made for the effects of the concentration polarization on the water permeance and the observed salt retention.

At the beginning of each filtration run, the 4" RO module was flushed with pretreated seawater under slight permeation during half a day to allow for the removal of preservation agents and to ensure that all air is purged following a procedure described in the technical manual provided by the membrane manufacturer [24]. Subsequent filtration was performed prior to chlorination to determine at the steady state the water permeance $(A)$ and salt retention $\left(R_{\text {obs }}\right)$ of the pristine RO module (an average permeate volume of $6 \mathrm{~m}^{3}$ was required). Furthermore, filtration was allowed to run for at least $48 \mathrm{~h}$ in between 2 successive chlorine injection steps in order to determine chlorinated RO module transport properties at the steady state.

Upon determining the water permeance and salt retention of the RO module for each free chlorine dose, $R_{\text {obs }}$ was monitored as a function of the permeation flux $\left(J_{\mathrm{w}}\right)$ by varying the mean applied pressure. In addition, samples from the permeate and feed streams were collected for the analysis of the ion composition and determination of the observed retention of each ion $\left(R_{\mathrm{obs}, i}\right)$ by using Eq. (3):

$R_{\mathrm{obs}, i}=1-{ }^{C_{\mathrm{p}, i}} /_{\mathrm{C}_{\mathrm{o}, i}}$

In Eq. (3), $C_{\mathrm{p}, \mathrm{i}}$ and $C_{\mathrm{p}, \mathrm{o}}$ correspond to the concentration of an ion in the permeate and in the bulk feed $\left(\mathrm{mg} \mathrm{L}^{-1}\right)$.

Prior to chlorination (see Section 2.4 for a complete description of the procedure used), filtration was stopped by reducing the applied pressure and by shutting down the high pressure pump.

\subsection{Chlorination protocol}

\subsubsection{Exposure of membrane samples}

Membrane samples extracted from an 8" spiral wound module and cut to a size of $4 \times 4 \mathrm{~cm}$ (for membrane surface elemental analysis, see Section 2.5.1) were soaked, at $20 \pm 3{ }^{\circ} \mathrm{C}$, in ca. $50 \mathrm{~mL}$ free chlorine solutions contained in borosilicate beakers covered with Parafilm $\mathrm{TM}$ and stored in a dark area. The free chlorine solutions were prepared by diluting a $111 \mathrm{~g} \mathrm{~L}^{-1}$ sodium hypochlorite $(\mathrm{NaOCl})$ solution in UP water to the desired concentrations (Table 2). The pH was adjusted by addition of hydrochloric acid 37\% v/v (Acros Organics) at values of 6.9 and 8.0 , corresponding to average pretreated seawater $\mathrm{pH}$ values found in desalination plants. The contact time was set to $1 \mathrm{~h}$. As described previously [14], the content of hypochlorous acid $(\mathrm{HOCl})$ and of the hypochlorite ion $\left(\mathrm{ClO}^{-}\right)$was spectrophotometrically determined at each $\mathrm{pH}$. As a result, the chlorine content at the membrane surface, determined by X-ray photoelectron spectroscopy (XPS, see Section 2.5.1), was monitored as a function of the $\mathrm{HOCl}$ dose (C.t), which corresponds to the product of the $\mathrm{HOCl}$ concentration and of the contact time, expressed in $\mathrm{mg} \mathrm{h} \mathrm{L}^{-1} \mathrm{HOCl}$ (ppm h HOCl). The chlorine to nitrogen ratio was used to express specifically the content of chlorine bounded to the PA layer, independently of the presence of a thin coating layer, consistent with a polyvinyl alcohol (PVA) [25]. Prior to elemental analysis performed by XPS, the chlorinated membrane samples were rinsed with UP water to remove free chlorine and stored in UP water in opaque covered containers at $4{ }^{\circ} \mathrm{C}$.

\subsubsection{Exposure of the 4" RO module}

At the pilot-scale, exposure of the RO membranes contained in the 4" spiral wound module was performed in similar conditions (active species, and by immersion). To achieve comparable chlorination conditions with those used at the lab-scale, free chlorine solutions were prepared by diluting $\mathrm{NaOCl}$ solutions in permeate (conductivity of ca. $100 \mu \mathrm{S} \mathrm{cm}^{-1}$ ) produced from the control (non-chlorinated) $4 "$ RO module. Prior to chlorination, the spiral wound module was rinsed by circulating the RO permeate, without permeation, until the conductivity of the effluent reached ca. $100 \mu \mathrm{S} \mathrm{cm}^{-1}$. Ion composition

\section{Table 2}

Free chlorine doses used for the analysis of the membrane surface elemental composition and during the chlorination of the RO modules at the pilot-scale, performed by periodic injections to achieve cumulated doses of 40,400, 1000, 2500 and $4000 \mathrm{ppm}$ h. Free chlorine solutions were prepared at a pH of 6.9 and 8.0 and at $20 \pm 3{ }^{\circ} \mathrm{C}$.

\begin{tabular}{llllllll}
\hline $\begin{array}{l}\text { Chlorination conditions Injected dose } \\
\text { at the pilot-scale }\end{array}$ & 40 & 360 & 600 & 1500 & 1500 & \\
$\begin{array}{l}\text { (ppm h) } \\
\text { Cumulated dose } \\
\text { (ppm h) }\end{array}$ & 40 & 400 & 1000 & 2500 & 4000 & \\
$\begin{array}{l}\text { Chlorination conditions } \\
\text { for the membrane } \\
\text { samples }\end{array}$ & $\begin{array}{l}\text { Free chlorine dose } \\
(\text { ppm h) }\end{array}$ & 40 & 100 & 400 & 1000 & 2500 & 4000 \\
& $\begin{array}{l}\text { HOCl dose at pH 6.9 } \\
(\text { ppm h) }\end{array}$ & 31.2 & 78 & 312 & 780 & 1950 & 3120 \\
& $\begin{array}{l}\text { HOCl dose at pH 8.0 } \\
(\text { ppm h) }\end{array}$ & - & 22 & 88 & 220 & - & 880 \\
\hline
\end{tabular}

${ }^{a} \mathrm{HOCl}$ doses at $\mathrm{pH} 6.9$ and 8.0 were converted from free chlorine doses by using $\mathrm{HOCl}$ molar fractions spectrophotometrically determined at each $\mathrm{pH}$. 
and trace metal concentration (specifically, aluminum, copper and iron known to catalyze PA chlorination in the presence of free chlorine [27]) of the permeate were determined (see Section 2.5.2). The analysis mainly shows that the permeate bromide ion concentration was lower than $0.1 \mathrm{mg} \mathrm{L}^{-1}$ and that it contained trace concentrations of $1 \mu \mathrm{g} \mathrm{L}^{-1} \mathrm{Cu}, 10 \mu \mathrm{g} \mathrm{L}{ }^{-1} \mathrm{Fe}$ and $80 \mu \mathrm{g} \mathrm{L}{ }^{-1} \mathrm{Al}$, naturally contained in the seawater influent and/or originating from the coagulation step. In addition, visual inspection of the surface of the membranes extracted from the 4" module following the entire filtration run revealed roughly no fouling layer (at most a heterogeneously covered surface), thus reducing the potential reaction of free chlorine with other compounds. These elements seem to support that reaction conditions were such that the free chlorine species, in the concentration and $\mathrm{pH}$ range studied (i.e., $\mathrm{HOCl}$ and $\mathrm{ClO}^{-}$), were the main reactants. The free chlorine solution was pumped into the module at the concentrate inlet, was allowed to flow up to the feed inlet (Fig. 1), without permeation, and was circulated back to the free chlorine stock tank by using a peristaltic pump and Nalgene ${ }^{\mathrm{TM}}$ polyethylene tubes, composing the circulation loop that replaced the pipes used during high pressure filtration. By using this procedure, the surface layer was the only layer of the composite RO membrane to be in contact with the free chlorine solutions. The $\mathrm{pH}$ was continuously monitored and the free chlorine concentration was determined at the start and end of the contact period.

Chlorination of the RO membranes contained in the spiral wound module was performed by a sequential increase of the free chlorine dose in between filtration runs to achieve successively free chlorine doses of 40,400,1000, 2500 and $4000 \mathrm{ppm}$ h (Table 2). As for the procedure used at the lab-scale, the contact time was set to $1 \mathrm{~h}$. The free chlorine concentration, determined by the titration method using DPD and the kit UV spectrometer $(\mathrm{HACH})$, decreased on average by less than $10 \%$ during the contact time. The $\mathrm{pH}$ of the free chlorine solutions was systematically adjusted at 6.9 by addition of $2 \mathrm{M}$ $\mathrm{HCl}$ (Sigma Aldrich) and the temperature was of $20 \pm 3{ }^{\circ} \mathrm{C}$. Both remained constant throughout the contact period. At the end of the contact time, the module was rinsed with the RO permeate to remove the free chlorine solution and further rinsed with seawater, without permeation, prior to resuming the high-pressure filtration.

\subsection{Elemental analysis}

\subsubsection{XPS}

The atomic composition of the surface layer (across the top $10 \mathrm{~nm}$ in depth) of membrane samples was obtained by XPS. XPS spectroscopy was performed with an Escalab 250 (Thermo Electron) XPS spectrometer using a monochromatic aluminum $K \alpha$ radiation as an X-ray excitation source $(1486.6 \mathrm{eV})$. A spot of the membrane sample of $400 \mu \mathrm{m}$ in diameter was scanned using this source. Membrane samples with sizes of ca. $4 \times 4 \mathrm{~cm}$ were mounted on a sample holder with graphite adhesive tape and kept overnight at high vacuum in the preparation chamber before they were transferred to the analysis chamber of the spectrometer. Avantage software was used for data acquisition and analysis. Survey XPS spectra were obtained by scanning over a $0-1200 \mathrm{eV}$ electron binding range with an energy step size of $1 \mathrm{eV}$. High resolution XPS core-level spectra were obtained by averaging 15 scans for $\mathrm{C} 1 \mathrm{~s}, \mathrm{O} 1 \mathrm{~s}, \mathrm{~N} 1 \mathrm{~s}$ and $\mathrm{Cl} 2 \mathrm{p}$ with an energy step size of $0.2 \mathrm{eV}$ and by using a $45^{\circ}$ takeoff angle. Membrane samples were irradiated separately and for a maximum time of $15 \mathrm{~min}$. All high resolution scans were normalized against the binding energy of the aromatic $\mathrm{C}=\mathrm{C}$ bond $(\mathrm{C} 1 \mathrm{~s}$ corrected to $284.6 \mathrm{eV}$ ). Atomic concentration percentages of $\mathrm{C}, \mathrm{O}, \mathrm{N}$, and $\mathrm{Cl}$ of the membranes before and after chlorination were determined using a semi-quantitative method, i.e. by assuming that $\mathrm{C}, \mathrm{N}, \mathrm{O}$ and $\mathrm{Cl}$ account for $100 \%$ of the elements present at the surface of the samples analyzed by XPS. The surface atomic concentrations were determined from photoelectron peak areas using the atomic sensitivity factors reported by Scofield
[28]. The background signal was subtracted using the Shirley method. Sample charging was minimized by an electron flood gun operated at $2 \mathrm{eV}$.

\subsubsection{Pretreated seawater ion and metal content}

The analysis of the ion content of the pretreated seawater and of the permeate produced by the RO module before chlorination and following exposure to each free chlorine dose used was performed by the Institut Départemental d'analyse, de conseil et d'expertise en Hygiène alimentaire, Eau, environnement et Santé Animale (IDHESA), analytical laboratory located in Plouzané (France). Atomic absorption spectroscopy was used to determine the concentration of potassium, sodium, calcium and magnesium ions, ion chromatography was used to determine the concentration of bromide and sulfate ions, and a titration method was applied to determine the concentration of chloride ions. The concentration of metals (aluminum, copper and iron) in the pretreated seawater was determined by inductively coupled plasma mass spectrometry, performed by IDHESA. Samples $(250 \mathrm{~mL}$ and $1 \mathrm{~L})$ were collected from the feed and permeate streams, stored at $4{ }^{\circ} \mathrm{C}$ before they were shipped to IDHESA for analysis. All methods were performed following international standard (ISO) procedures.

\section{Results and discussion}

\subsection{Assessment of chlorination conditions}

Elemental composition of the surface of membrane samples, extracted from an 8" module, was monitored for the free chlorine doses spanned to provide insights on the reactivity of PA presumably experienced at the pilot-scale. Fig. 2 presents the chlorine to nitrogen atomic percent ratio determined at the very top surface of membrane samples by XPS for the different doses used at pH 6.9 and 8.0. A peak at $200.3 \mathrm{eV}$ assignable to covalently bound chlorine [6,29] and a peak at $399.9 \mathrm{eV}$ assigned to the - $\mathrm{NH}$ bond [26], respectively determined by deconvoluting the high resolution XPS spectra of $\mathrm{Cl} 2 \mathrm{p}$ and $\mathrm{N} 1 \mathrm{~s}$, were compared. The chlorination of PA, monitored ca. at the top $10 \mathrm{~nm}$ of this layer, seems to depend on the concentration of $\mathrm{HOCl}$ in the conditions used (free chlorine dose, solution $\mathrm{pH}$ ). This is in agreement with results previously reported for the chlorination of aliphatic and aromatic linear and crosslinked polyamide [30,5,14]. Furthermore, the incorporation of chlorine seems to level off at a dose of $1000 \mathrm{ppm} \mathrm{h} \mathrm{HOCl}$, in agreement with previously published XPS results on PA halogenation [31]. The chlorine to nitrogen ratio is ca. $1: 1$ roughly at this dose and up to $3120 \mathrm{ppm} \mathrm{h} \mathrm{HOCl}$, highest exposure dose also used during the pilot-scale study.

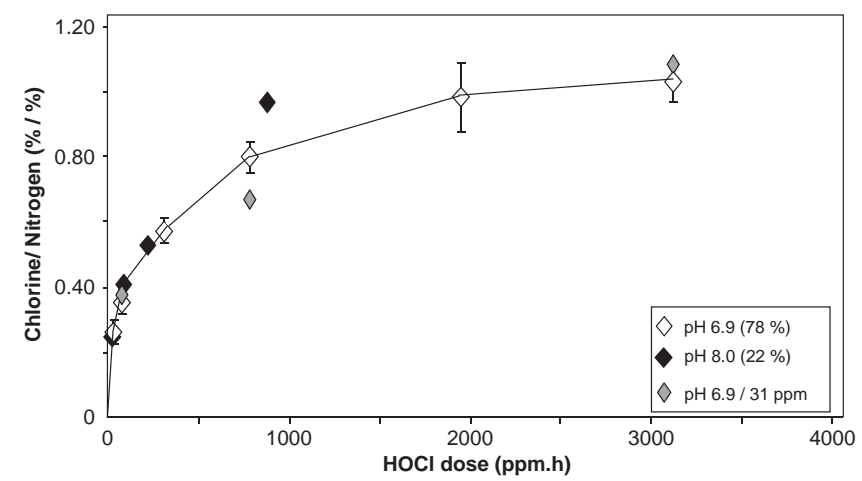

Fig. 2. Ratio of PA bound chlorine to nitrogen (atomic percent determined by XPS) as a function of $\mathrm{HOCl}$ dose (exposure time of $1 \mathrm{~h}$ ). The ratio was also determined for samples immersed in $31 \mathrm{ppm} \mathrm{HOCl}$ and for exposure durations of 2.5, 25 and $100 \mathrm{~h}$, leading to equivalent $\mathrm{HOCl}$ doses of 78,780 and 3120 ppm h. Free chlorine doses used at pH 6.9 and 8.0 were converted to $\mathrm{HOCl}$ dose by using $\mathrm{HOCl}$ molar fractions (given in parenthesis) spectrophotometrically determined at these $\mathrm{pH}$ values. Error bars were defined from standard deviations obtained for 3 separate experiments. 
In addition, Fig. 2 presents the chlorine to nitrogen ratio determined for membrane samples exposed to a $\mathrm{HOCl}$ concentration of ca. $31 \mathrm{ppm}$, the lowest concentration used, for contact times of 2.5, 25 and $100 \mathrm{~h}$, respectively leading to equivalent $\mathrm{HOCl}$ doses of 78 , 780 and $3120 \mathrm{ppm} \mathrm{h}$. In the $\mathrm{HOCl}$ dose spanned, from 31 to $3120 \mathrm{ppm}$ h, the chlorine to nitrogen ratio did not vary over $15 \%$ regardless of the C.t combinations used, specifically during so-called accelerated exposure conditions as opposed to potential on-site exposure conditions (comparatively achieved at a lower concentration and for a longer exposure period). Elemental analysis by XPS of the surface of membrane samples show, to some extent, that the chlorination protocol used at the pilot-scale (by a sequential increase of the $\mathrm{HOCl}$ dose) should not interfere with the comparison of RO performance changes between those observed at the lab-scale (using a cross-flow filtration cell) and those monitored in the present study at the pilot-scale during the filtration of a pretreated seawater using 4 " RO modules.

\subsection{Performance of chlorinated RO modules during desalination}

Independent filtration runs and analysis of chlorination-induced performance changes were performed with two 4" RO modules. Each module operated during ca. 1 week (achieving the production of a permeate volume of $6 \mathrm{~m}^{3}$ ) to determine at the steady state the pristine RO membrane permeance to water and salt retention. Fig. 3 presents the variation of the observed salt retention $\left(R_{\text {obs }}\right)$ with the permeation flux $\left(J_{\mathrm{w}}\right)$ for both modules. They exhibited a salt retention (determined by conductivity) of $99.8 \%$ at the operating permeation flux of $21 \mathrm{~L} \mathrm{~h}^{-1} \mathrm{~m}^{-2}, 20^{\circ} \mathrm{C}$. This result is in agreement with the average value provided by the manufacturer, i.e. 99.75\% [24]. In addition, at this permeation flux, the retention of target ions was on average of $99.8 \%$ and was complete for divalent ions (data not shown). The water permeance of each module remained roughly unchanged during the time span prior to chlorination (Fig. 4), and the average value was equal to $0.91 \mathrm{~L} \mathrm{~h}^{-1} \mathrm{~m}^{-2} \mathrm{bar}^{-1}, 20^{\circ} \mathrm{C}$.

Fig. 4 presents the evolutions of $A$ and $R_{\text {obs }}$ with the chlorination of a module, performed by a sequential increase of the free chlorine dose. Profiles that are presented for $A$ and $R_{\mathrm{obs}}$ are characteristic for both modules, with respect to both chlorination-induced changes in the value of each parameter and to their time dependence. The latter point will be discussed more in detail in Section 3.3 in relation to the increase of salt permeation through the chlorinated PA layer and its impact on inducing swelling of this layer. RO performance was monitored during the filtration of a pretreated seawater for a minimum of $48 \mathrm{~h}$ following a total exposure dose of 40 and $2500 \mathrm{ppm}$ h free chlorine, and up to $170 \mathrm{~h}$ after exposure to a total dose of 400,1000 and

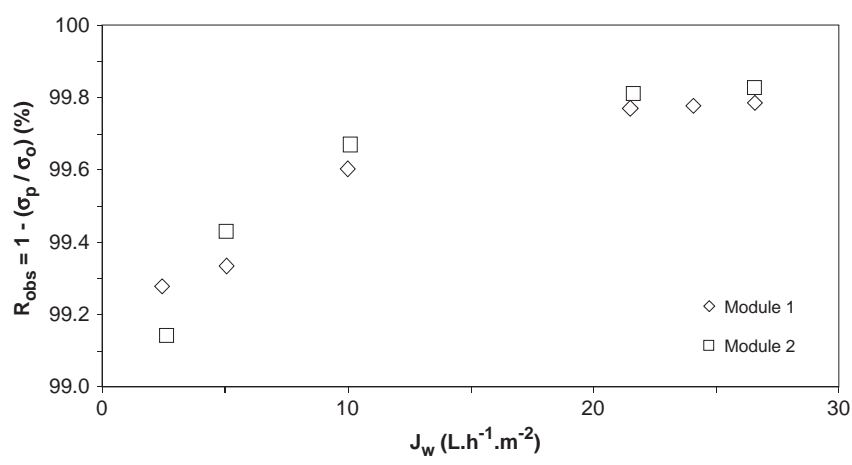

Fig. 3. Observed salt retention of 2 pristine RO modules operated at different periods as a function of the permeation flux (pretreated seawater, module 1 operated from December 2010 to January 2011 and module 2 from January to February 2011). RO module salt retention was determined from conductivity measurements of the bulk feed $\left(\sigma_{\mathrm{o}}\right)$ and of the permeate $\left(\sigma_{\mathrm{p}}\right)$.
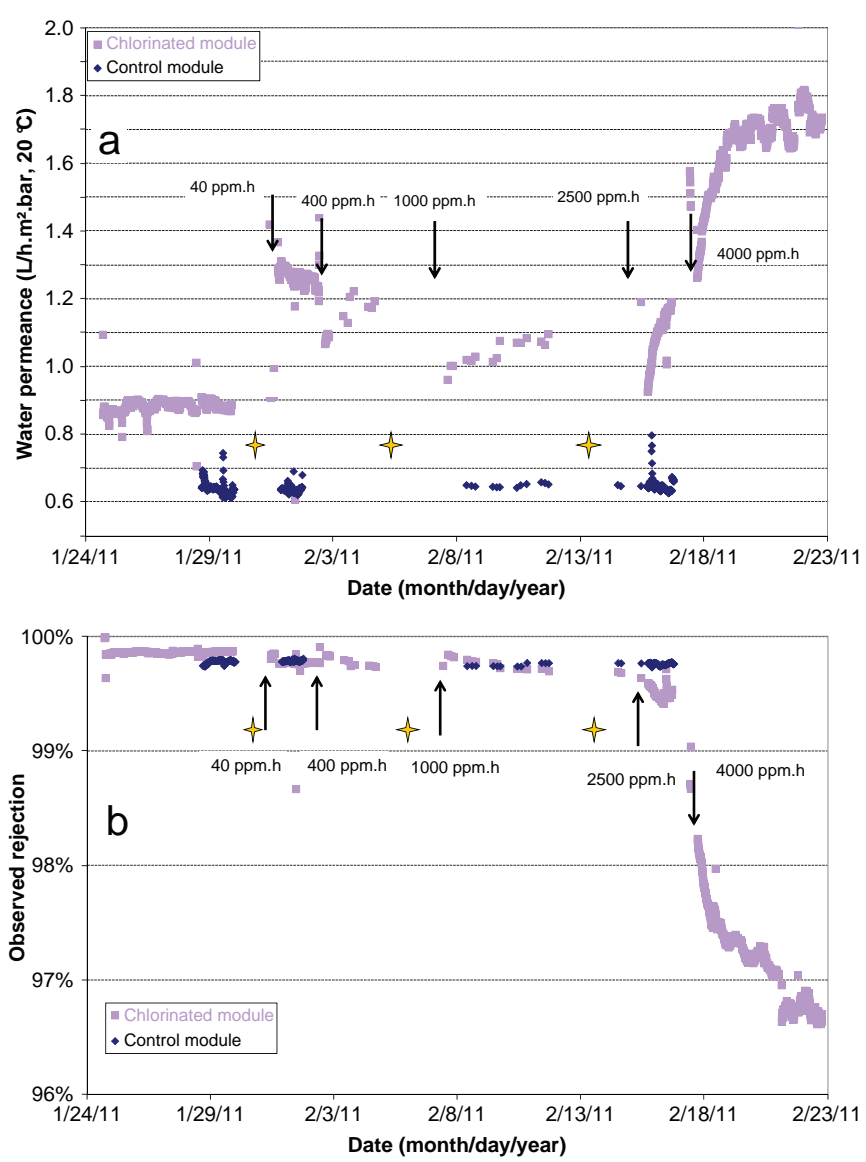

Fig. 4. a) Water permeance and b) Observed salt retention variations with an increase in the free chlorine dose as monitored during the month long filtration run performed on module \# 2. ( $\downarrow$ ) indicates the time at which free chlorine was injected to increment the cumulated dose of exposure $(40,400,1000,2500$ and $4000 \mathrm{ppm} \mathrm{h}$, at pH 6.9). (\$) signals a period during which the RO units were shutdown. The permeation flux was maintained constant at $21 \mathrm{~L} \mathrm{~h}^{-1} \mathrm{~m}^{-2}, 20{ }^{\circ} \mathrm{C}$

$4000 \mathrm{ppm}$ h free chlorine, at $\mathrm{pH}$ 6.9. Instantaneous changes in the values of $A$ and of $R_{\text {obs }}$ were observed when filtration was resumed following the chlorination of a module, regardless of the free chlorine dose reached. Water permeance and salt retention of the control module (non-chlorinated) were unchanged during the same period. Results presented in Fig. 4 indicate that the water permeance and to a lesser extent the observed salt retention are modified at free chlorine doses below the threshold value provided by the manufacturer, i.e. $1000 \mathrm{ppm} \mathrm{h,} \mathrm{which} \mathrm{is} \mathrm{consistent} \mathrm{with} \mathrm{the} \mathrm{changes} \mathrm{in} \mathrm{PA}$ elemental, chemical composition, mechanical properties and structure reported here (Fig. 2 ) and in the literature $[13,14,17,19]$. In addition, the chlorination protocol used (sequential increase of the free chlorine dose) and the filtration runs performed with 4" RO modules confirm that $A$ and $R_{\text {obs }}$ are free chlorine dose dependent. As such, variations observed at the pilot-scale were comparable to those reported at the lab-scale [14,18-20] despite main differences in the filtration protocol (absence of pure water filtration at the pilot-scale), hydrodynamic conditions, water composition (generally single solute aqueous solutions are used for tests performed by using filtration cells) and transport properties of pristine membrane samples [32]. Remarkably, the changes in the values of $A$ and of $R_{\text {obs }}$ following exposure to a total free chlorine dose of 40 and $400 \mathrm{ppm}$ $\mathrm{h}$ were quantitatively similar to those observed during the filtration of a $0.55 \mathrm{M} \mathrm{NaCl}$ single-solute aqueous solution performed at the lab-scale (Table 3 ). This is consistent with changes of characteristic PA infrared absorbance bands which were observed to be similar to 
Table 3

Comparing water permeance $(A)$ and salt retention $\left(R_{\text {obs }}\right)$ variations following an exposure to free chlorine doses of 40 and $400 \mathrm{ppm} \mathrm{h}$, at pH 6.9, determined at the lab-scale and at the pilot-scale.

\begin{tabular}{llllll}
\hline Cumulated free chlorine dose $(\mathrm{ppm} \mathrm{h})$ & 40 & \multicolumn{4}{l}{400} \\
\hline Parameter & $A$ & $R_{\text {obs }}$ & $A$ & $R_{\text {obs }}$ \\
Variation observed at the lab-scale (\%) & +50 & -0.8 & +20 & -0.3 \\
Variation observed at the pilot-scale (\%) & +33 & -0.1 & +31 & -0.1 \\
\hline
\end{tabular}

a Results at the lab-scale were determined during the filtration of a $0.55 \mathrm{M} \mathrm{NaCl}$ aqueous solution at a permeation flux of $31 \mathrm{~L} \mathrm{~h}^{-1} \mathrm{~m}^{-2}$ performed with a cross flow filtration cell [20].

those reported for membrane samples under accelerated exposure conditions $[14,19]$. Infrared spectroscopy (ATR-FTIR) was performed on the surface of RO membrane sheets extracted from a 4" module at random locations following a filtration run, i.e. after exposure of the module to a cumulated free chlorine dose of $4000 \mathrm{ppm} \mathrm{h}$, at pH 6.9 (data not shown). These surface chemical analyses seem to further support the relevance of accelerated chlorine exposure conditions used at the lab-scale in simulating potential on-site reaction conditions, for the reaction conditions used during this study (doses spanned and species considered).

Furthermore, the chlorination protocol used during this study seems to indicate that periodic and repeated exposure to free chlorine irreversibly causes a loss in RO water/salt selectivity during the filtration in usual seawater $\mathrm{pH}$ conditions, i.e. at ca. $\mathrm{pH} 8$.

Tentative structure-property relations were proposed. They generally link a chlorine-induced increase in chain mobility within the PA layer to changes in transfer properties of commercially available asymmetric [7] and composite RO membranes [14,19,33]. The free chlorine dose dependence of $A$ and of $R_{\text {obs }}$ demonstrated during the sequential chlorination and long term seawater filtration tests and characteristic evolutions attributed to chlorination, such as the time dependence of water permeance, suggest that variations of $A$ could be used to monitor membrane chlorination continuously and in a non-destructive way. On the one hand, as demonstrated at the labscale [14], chlorination in controlled conditions, i.e. at $40 \mathrm{ppm}$ h the lowest free chlorine dose used in this study, increased the permeation flux by $24 \%$, alternatively decreased the applied pressure required by $14 \%$ compared to nominal operating conditions without compromising RO salt retention. On the other hand, a progressive increase of the free chlorine dose above $1000 \mathrm{ppm}$ h caused both water permeance and salt passage to increase, leading to an overall loss of RO membrane selectivity. Following a cumulated exposure to a free chlorine dose of $4000 \mathrm{ppm} \mathrm{h}$, at the steady state (reached after $170 \mathrm{~h}$ of filtration), $A$ was determined to have increased overall by a factor of 2 while $R_{\mathrm{obs}}$ decreased by $3.2 \%$ compared to baseline values obtained with the pristine module. In addition, at the steady state $A$ decreased with an increase in the free chlorine dose from 40 to 400 and $1000 \mathrm{ppm} \mathrm{h}$, which would be consistent with an applied pressure-induced decrease of $A$ reported in a previous study [14]. Moreover, $A$ was observed to increase with time during the filtration for an exposure to free chlorine of $400 \mathrm{ppm} \mathrm{h}$ and above, in agreement with previous results reported by lab-scale studies $[19,20]$. The higher the free chlorine dose of exposure, the higher the rate of increase of $A$ with time $\left(A^{\prime}\right)$. Following a cumulated and maximal exposure to a free chlorine dose of $4000 \mathrm{ppm} \mathrm{h}$, at $\mathrm{pH} 6.9, A^{\prime}$ reached a value of $0.3 \mathrm{~L} \mathrm{~h}^{-2} \mathrm{~m}^{-2} \mathrm{bar}^{-1}$ in the time span of $3 \mathrm{~h}$, an order of magnitude lower than the value determined at the lab-scale in similar chlorination conditions. At the same time, $R_{\mathrm{obs}}$ decreased by ca. 3.0\% between an exposure to a cumulated free chlorine dose of 1000 and $4000 \mathrm{ppm} \mathrm{h}$. In agreement with a recent study [20], this result could indicate that the apparent recovery of $A$ of a chlorinated membrane is triggered essentially with the permeation of a salt across the PA layer. Further description of this phenomenon is provided in Section 3.3.
3.3. Identification of the transport properties of chlorinated PA-based RO membranes

Fig. 5 presents the retention of target mono- and divalent ions $\left(R_{\mathrm{obs}, i}\right)$, determined by elemental analysis and at a permeation flux of $21 \mathrm{~L} \mathrm{~h}^{-1} \mathrm{~m}^{-2}, 20{ }^{\circ} \mathrm{C}$, as a function of the different free chlorine doses reached consecutively. Average values determined for both chlorinated RO modules essentially show that divalent ions are fully retained (a maximum decrease of $0.1 \%$ was reached for $\mathrm{Mg}^{2+}$ ) while the retention of monovalent ions decreased in a non linear fashion with an increase in the free chlorine dose. Sodium and bromide ions were specifically less rejected from the chlorinated membrane, their retention decreasing from $99.6 \%$ to ca. $96 \%$ with an increase of the free chlorine dose from 1000 to $4000 \mathrm{ppm}$ h. From an end-user standpoint, the RO salt retention, in particular of bromide ions, decreased below a threshold value of $99.6 \%$ following the exposure to a cumulated free chlorine dose of $1000 \mathrm{ppm} \mathrm{h}$, at pH 6.9, corresponding to chlorination conditions under which the chlorine content of the PA surface was observed to level off (Fig. 2).

Fig. 5 shows that the divalent cations and anions were fully rejected, whatever the level of membrane chloration covered in the present study. However, the retention of monovalent ions decreased in a continuous way as long as the exposure to free chlorine increased. The electroneutrality condition, given that the permeate contained only monovalent ions, explains that the retention rates of the anions and of the cations were similar. To some extent, these chlorinated RO membranes have a very high selectivity for monovalent-divalent ion mixtures, similar to those found for nanofiltration. However, here the retention of divalent ions, even at a high free chlorine concentration, reaches almost $100 \%$. Considering the high ionic strength of the feed solution, and given that the chlorinated membrane remains an RO membrane with a low charge density [34], the monovalent-divalent ion selectivity can presumably not be ascribed to charge exclusion, but rather to size exclusion.

In a recent study, filtration experiments performed with single-solute aqueous solutions containing alternatively mono-, divalent salts and a neutral organic solute have shown that the chlorinated (and as a result less rigid) PA layer was subject to swelling with the permeation of a salt [20]. This relaxation phenomenon was associated to the continuous increase of $A$ with time and was shown to depend on the initial salt flux. Based on these explanations, salt retention results provided in Fig. 5 could indicate that monovalent ions, as they permeate preferentially through the chlorinated membrane, generate the increase of $A$ with time, mainly observed above a free chlorine dose of $1000 \mathrm{ppm} \mathrm{h}$

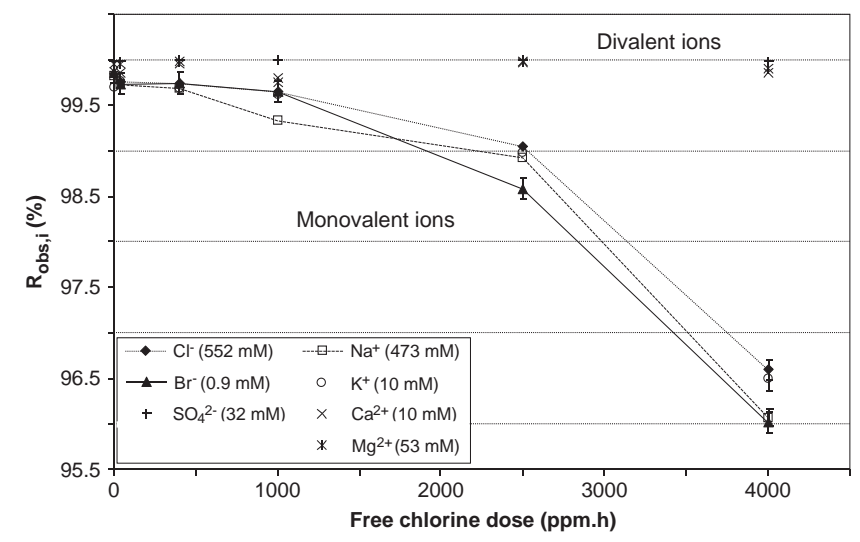

Fig. 5. Observed ion retention of the chlorinated RO module (no. 2) during the reverse osmosis of a pretreated seawater (Toulon, France). Bulk feed concentration (pretreated seawater) of each mono- and divalent ions are provided in between parenthesis. Chlorination was performed by a sequential increase of the free chlorine dose from 0 up to 40,400,1000, 2500 and $4000 \mathrm{ppm}$ h, at pH 6.9. Errors bars were defined from standard deviations obtained during the two independent filtration runs. 
matching conditions under which the retention of monovalent ions decreased more significantly (Fig. 4).

\section{Conclusion}

A pilot-scale study was conducted to assess RO membrane water permeance and salt retention variations induced by chlorination and to compare them with those observed at the lab-scale. A chlorination protocol was transposed from previous works from the lab-scale and adapted to expose only the surface active layer of the composite membrane to consecutive free chlorine doses ranging from 40 to $4000 \mathrm{ppm}$ $\mathrm{h}$, at $\mathrm{pH}$ 6.9. Under $\mathrm{pH}$ conditions usually found in desalination plants, elemental analysis of the surface of chlorinated membranes performed by XPS showed that chlorination is controlled by the concentration of $\mathrm{HOCl}$, independently of the C.t combinations used. The filtration of a pretreated seawater was performed by using 4" RO spiral wound modules. In agreement with previously published results obtained at the lab-scale, $A$ and $R_{\text {obs }}$ were observed to be free chlorine dose dependent. Main results regarding the performance of chlorinated PA-based RO membranes, now confirmed at the pilot-scale during the filtration of seawater, are:

- The water/salt selectivity of an RO membrane can be increased after exposure to a free chlorine dose of $40 \mathrm{ppm}$ h and below $400 \mathrm{ppm} \mathrm{h}$, at $\mathrm{pH}$ 6.9.

- Above the free chlorine dose threshold value of $1000 \mathrm{ppm}$, the membrane water/salt selectivity, in particular to bromide ions, is irreversibly lost.

Long-term filtration tests unambiguously demonstrated that transport property variations, mainly the values of $A$ and the rate of increase of $A$ with time, a characteristic property of chlorinated PA-based membranes, were instantaneous when filtration was resumed following an exposure to free chlorine, irrespective of the dose reached. The elemental analysis of the feed and permeate streams revealed that monovalent ions of the pretreated seawater, containing mainly sodium, chloride and bromide ions at a concentration of $69 \mathrm{mg} \mathrm{L}^{-1}$, were less rejected by the chlorinated membrane than divalent ions. It was further suggested that the permeation of monovalent ions contributed to the increase of $A$ with time, related to a swelling-induced relaxation process of the chlorinated (and as a result less rigid) PA layer, following the exposure to a cumulated free chlorine dose of $1000 \mathrm{ppm} \mathrm{h}$ and up to $4000 \mathrm{ppm} \mathrm{h}$.

\section{Acknowledgements}

The authors wish to thank J-.F. Laroche, A. Davaillon, and I. Labaye from Veolia Environnement for their assistance and valuable recommendations during the pilot-scale study and Valérie Flaud from the Institut Charles Gerhardt (Montpellier, France) for performing the XPS analysis. Veolia Environnement is gratefully acknowledged for funding this work.

\section{References}

[1] G.M. Geise, H.S. Lee, D.J. Miller, B.D. Freeman, J.E. McGrath, D.R. Paul, Water purification by membranes: the role of polymer science, J. Polym. Sci. B Polym. Phys. 48 (2010) 1685-1718.

[2] J. Benavente, M.I. Vázquez, Effect of age and chemical treatments on characteristic parameters for active and porous sublayers of polymeric composite membranes, J. Colloid Interface Sci. 273 (2004) 547-555.

[3] M. Nilsson, G. Trägardh, K. Östergren, Influence of temperature and cleaning on aromatic and semi-aromatic polyamide thin-film composite NF and RO membranes, Sep. Purif. Technol. 62 (2008) 717-726.

[4] J.E. Cadotte, R.J. Petersen, R.E. Larson, E.E. Erickson, A new thin-film composite seawater reverse osmosis membrane, Desalination 32 (1980) 25-31.
[5] J. Glater, M.R. Zachariah, S.B. McCray, J.W. McCuthan, Reverse osmosis membrane sensitivity to ozone and halogen disinfectants, Desalination 48 (1983) 1-16.

[6] J.Y. Koo, R.J. Petersen, J.E. Cadotte, ESCA characterization of chlorine-damaged polyamide reverse osmosis membrane, ACS Polym. Prepr. 27 (1986) 391-392.

[7] S. Avlonitis, W.T. Hanbury, T. Hodgkiess, Chlorine degradation of aromatic polyamides, Desalination 85 (1992) 321-334.

[8] N.P. Soice, A.C. Maladono, D.Y. Takigawa, A.D. Norman, W.B. Krantz, A.R. Greenberg, Oxidative degradation of polyamide reverse osmosis membranes: studies of molecular model compounds and selected membranes, J. Appl. Polym. Sci. 90 (2003) 1173-1184.

[9] A. Subramani, E.M.V. Hoek, Biofilm formation, cleaning, re-formation on polyamide composite membranes, Desalination 257 (2010) 73-79.

[10] T. Knoell, E. Martin, K. Ishida, D. Phipps, The effect of chlorine exposure on the performance and properties of polyamide reverse osmosis membranes, Awwa Membrane Technical Conference proceedings, 2005.

[11] J.Y. Koo, J.H. Lee, Y.D. Jung, S.P. Hong, S.R. Yoon, Chlorine resistant membrane and the mechanism of membrane degradation by chlorine, Awwa Membrane Technology Conference proceedings, 2009.

[12] J. Glater, M.R. Zachariah, A mechanistic study of halogen interaction with polyamide reverse-osmosis membranes, ACS Symp. Ser. 281 (1985) 345-358.

[13] Y.N. Kwon, C.Y. Tang, J.O. Leckie, Change of chemical composition and hydrogen bonding behavior due to chlorination of crosslinked polyamide membranes, J. Appl. Polym. Sci. 108 (2008) 2061-2066.

[14] A. Ettori, E. Gaudichet-Maurin, J.C. Schrotter, P. Aimar, C. Causserand, Permeability and chemical analysis of aromatic polyamide based membranes exposed to sodium hypochlorite, J. Membr. Sci. 375 (2011) 220-230.

[15] J.E. Glater, S.K. Hong, M. Elimelech, The search for a chlorine-resistant reverse osmosis membrane, Desalination 95 (1994) 325-345.

[16] A. Akdag, H.B. Kocer, S.D. Worley, R.M. Broughton, T.R. Webb, T.H. Bray, Why does Kevlar decompose, while Nomex does not, when treated with aqueous chlorine solutions? J. Phys. Chem. B 111 (2007) 5581-5586.

[17] J.Y. Chung, J.-.H. Lee, K.L. Beers, C.M. Stafford, Stiffness, strength, and ductility of nanoscale thin films and membranes: a combined wrinkling-cracking methodology, Nano Lett. 11 (2011) 3361-3365.

[18] S.H. Maruf, D.U. Ahn, J. Pellegrino, J.P. Killgore, A.R. Greenberg, Y. Ding, Correlation between barrier layer $T_{\mathrm{g}}$ and a thin-film composite membrane's performance: effect of chlorine treatment, J. Membr. Sci. 405 (2012) 167-175.

[19] Y.N. Kwon, J.O. Leckie, Hypochlorite degradation of crosslinked polyamide membranes II. Changes in hydrogen bonding behavior and membrane performance, J. Membr. Sci. 282 (2006) 456-464.

[20] A. Ettori, E. Gaudichet-Maurin, P. Aimar, C. Causserand, Mass transfer properties of chlorinated aromatic polyamide reverse osmosis membranes, Sep. Purif. Technol. 101 (2012) 60-67.

[21] U. von Gunten, Ozonation of drinking water: Part II. Disinfection and by-product formation in presence of bromide, iodide or chlorine, Water Res. 37 (2003) 1469-1487.

[22] P.G. Pope, G.E. Speitel Jr., Reactivity of bromine-substituted haloamines in forming haloacetic acids, ACS Symp. Ser. 995 (2008) 182-197.

[23] H. Shemer, R. Semiat, Impact of halogen based disinfectants in seawater on polyamide RO membranes, Desalination 273 (2011) 179-183.

[24] Dow Filmtec Technical Manual, July 2005

[25] C.Y. Tang, Y.N. Kwon, J.O. Leckie, Probing the nano- and micro-scales of reverse osmosis membranes - A comprehensive characterization of physicochemical properties of uncoated and coated membranes by XPS, TEM, ATR-FTIR, and streaming potential measurements, J. Membr. Sci. 287 (2007) 146-156.

[26] C.Y. Tang, Y.N. Kwon, J.O. Leckie, Effect of membrane chemistry and coating layer on physicochemical properties of thin film composite polyamide RO and NF membranes. I. FTIR and XPS characterization of polyamide and coating layer chemistry, Desalination 242 (2009) 149-167.

[27] C.J. Gabelich, J.C. Frankin, F.W. Gerringer, K.P. Ishida, I.H. Suffet, Enhanced oxidation of polyamide membranes using monochloramine and ferrous ion, J. Membr. Sci. 258 (2005) 64-70.

[28] J.H. Scofield, Hartree-Slater subshell photoionization cross-sections at 1254 and 1487 eV, J. Electron Spectrosc. Relat. Phenom. 8 (1976) 129-137.

[29] E.T. Kang, K.G. Neoh, K.L. Tan, Polyaniline: a polymer with many interesting intrinsic redox states, Prog. Polym. Sci. 23 (1998) 277-324.

[30] N. Dam, P.R. Ogilby, On the mechanism of polyamide degradation in chlorinated water, Helv. Chim. Acta 84 (2001) 2540-2549.

[31] Y.N. Kwon, R. Joksimovic, I.C. Kim, J.O. Leckie, Effect of bromide on the chlorination of a polyamide membrane, Desalination 280 (2011) 80-86.

[32] S.T. Mitrouli, A.J. Karabelas, N.P. Isaias, Polyamide active layers of low pressure RO membranes: data on spatial performance non-uniformity and degradation by hypochlorite solutions, Desalination 260 (2010) 91-100.

[33] S.D. Arthur, Structure-property relationship in a thin film composite reverse osmosis membrane, J. Membr. Sci. 46 (1989) 243-260.

[34] V.T. Do, C.Y. Tang, M. Reinhard, J.O. Leckie, Degradation of polyamide nanofiltration and reverse osmosis membranes by hypochlorite, Environ. Sci. Technol. 46 (2012) 852-859. 